\title{
Research Paper: Acceptance and Commitment Therapy Improves Psychological Flexibility of Students with Thalassemia Major: A Randomized Controlled Trial
}

\author{
Homeira Mahmoudi Souran', Gholam Reza Sanagouyemoharer ${ }^{*}$ (D), Mahmoud Shirazi²
}

1. Department of Psychology, Zahedan Branch, Islamic Azad University, Zahedan, Iran.

2 Department of Psychology, Faculty of Educational Sciences and Psychology, University of Sistan and Baluchestan, Zahedan, Iran

\begin{tabular}{|c|c|}
\hline $\begin{array}{l}\text { Use your device to san } \\
\text { and read the article online }\end{array}$ & Citation: Mahmoudi Souran, H., Sanagouyemoharer, Gh, R., \& Shirazi, M. (2019). Acceptance and Commitment Therapy \\
\hline 口部和回 & Improves Psychological Flexibility of Students with Thalassemia Major: A Randomized Controlled Trial. Journal of Practice in \\
\hline Hidin & Clinical Psychology, 7(2), 107-116. http://dx.doi.org/10.32598/jpcp.7.2.107 \\
\hline Ditipat & doijhttp://dx.doi.org/10.32598/jpcp.7.2.107 \\
\hline
\end{tabular}

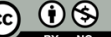

Article info:

Received: 06 Sep 2018

Accepted: 16 Jan 2019

Available Online: 01 Apr 2019

Keywords:

Acceptance and commitment therapy, Cognitive flexibility, Thalassemia major, Student

\section{ABSTRACT}

Objective: Acceptance and Commitment Therapy (ACT) tries to increase the psychological acceptance of individuals during mental experiences (thoughts, emotions, etc.) and to decrease their ineffective control of behaviors. This study aimed to determine the impact of ACT on the psychological flexibility of students with thalassemia in Zahedan City, Iran.

Methods: The present study was a quasi-experimental interventional study with experimental and control/ waiting groups. The subjects were evaluated in the pre-test, post-test, and two-month follow-up stages. The statistical population included all students with thalassemia studying in senior elementary and junior high schools in Zahedan. A total of 60 volunteers were selected and randomly assigned into two groups (control and experimental), each one including 30 subjects. The research tool was the Psychological Flexibility Test. ACT was conducted during 8 sessions (Two 120-minute sessions per week during one month), and a follow-up test was taken two months after the end of the intervention. The study data were analyzed through repeated measures analysis of variance.

Results: The results indicated a significant effect of ACT on increasing the cognitive flexibility in patients with thalassemia and supported the stability of this psychotherapy at the follow-up stage $(\mathrm{F}=63.823, \mathrm{P}=0.001)$.

Conclusion: ACT can be used to increase cognitive flexibility and to treat psychological disorders. Comparing cognitive flexibility scores of the samples in the pre-test, post-test, and follow up stages suggest that ACT is an effective method for improving cognitive flexibility in students with thalassemia major.

\section{* Corresponding Author:}

Gholam Reza Sanagouyemoharer, $P h D$.

Address: Department of Psychology, Zahedan Branch, Islamic Azad University, Zahedan, Iran.

Tel: +98 (915) 1491448

E-mail: gsanagouyemoharer@gmail.com 


\section{Highlights}

- Children with thalassemia major have significantly lower psychological flexibility compared to healthy children.

- Acceptance and commitment therapy belongs to the cognitive behavioral therapy tradition.

- Performing acceptance and commitment therapy workshop significantly increases psychological flexibility of the children with thalassemia major.

\section{Plain Language Summary}

Thalassemia is a chronic disease, and many children in our country suffer from this disease. Children with this disease commonly show lower psychological flexibility compared to healthy children. In this study, we investigated the effectiveness of acceptance and commitment therapy method, which is a safe, cost-effective, and easy to perform method to help patients manage their psychological problems related to thalassemia. The results indicate that this treatment is an effective method to increase the mental flexibility of the study patients.

\section{Introduction}

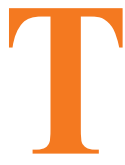

halassemia is one of the most common hereditary disorders that impose a lot of costs in the health care system around the world and Iran (Yaghobi et al., 2017). About 240 million individuals have major thalassemia worldwide, and currently, there are 22000 individuals with thalassemia major live in Iran (Abolghasemi et al., 2007). The province of Sistan and Baluchistan, located in the southeastern of Iran, hosts about $10 \%$ of patients with thalassemia in Iran. In other words, 2500 patients with thalassemia major live in Sistan and Baluchistan Province (Yaghobi et al., 2017). Today, the physiological condition of patients with thalassemia major has improved significantly using various therapies, such as blood transfusion and iron chelation drugs. However, their psychosocial problems have remained critical, considering the age of these patients (Padhi, Maharshi, Gupta, Garg, \& Nijhawan, 2018).

Clinical signs of thalassemia appear since the age of 6 months and lead to a wide range of serious clinical and psychological challenges (Abolghasemi et al., 2007). The children and adolescent patients with major thalassemia are especially vulnerable and manifest more emotional and behavioral problems (Yengil et al., 2014). Some studies indicate that thalassemia patients have lower life quality index than healthy people (Padhi et al., 2018). The previous studies have reported that $47 \%$ of patients have some anxiety and depression signs. Even patients with thalassemia minor show more depression compared to healthy subjects that cause problems in their self-care.
Depression in these patients is the result of the chronic nature of this disease; long-term treatment; an early death expectancy; the person's facial changes; and reactions seen from family, community, and friends (Shafiee, Nazari, Jorjani, Bahraminia, \& Sadeghi-Koupaei, 2014). In addition, research studies have shown that people with thalassemia have difficulty in adaptation and interactions with their environment (are not as flexible as healthy people). Some evidence indicates that cognitive flexibility is related to psychological well-being and vulnerability in a wide range of psychiatric disorders, including depression, anxiety, and so on (Masuda \& Tully, 2012).

Additionally, cognitive flexibility is associated with better physical, psychosocial, and emotional performance in psychotherapy processes (McCracken \& Jones, 2012). In other words, cognitive flexibility is the ability to connect to the present moment, to experience a painful situation in a meaningful manner, and to behave based on personal values (Hayes \& Strosahl, 2004). Moreover, cognitive flexibility insists on adaptive functioning approach instead of avoidance. This psychological approach trains individuals to be active in the thinking patterns and focuses on the goals and values rather than problems (Scott, Daly, Yu, \& McCracken, 2017).

The cognitive flexibility model assumes that a high level of acceptance, awareness, and commitment is associated with better health and performance (McCracken \& Morley, 2014). Acceptance and Commitment Therapy (ACT) is a psychotherapy method that is specifically designed and developed to improve cognitive flexibility (Hayes, Pistorello, \& Levin, 2012). ACT belongs to the "third wave" of cognitive behavioral therapy, and its efficacy has been proved in 
a wide range of disorders (Clarke, Kingston, James, Bolderston, \& Remington, 2014; Harley, 2015). ACT has six main processes that eventually leads to mental and cognitive flexibility in individuals. These six processes include acceptance, defusion, self-as-context, contact with the present moment, values, and committed action (Kelso, 2017). Kashdan and Rotterburg (2010) determined cognitive flexibility as the measure of how a person responds to situational demands; reconfigures mental resources; shifts perspective; balances competing desires, needs, and life domains.

McCracken and Jones (2012), research has shown that cognitive flexibility components, i.e. general acceptance, pain acceptance, mindfulness, and value-based functioning, had significantly improved after ACT-based therapy. Another study on the role of cognitive flexibility as the basic mechanism for change in the ACT shows that cognitive flexibility leads to the optimization of treatment effect (Gandy et al., 2018). Also, another study shows that the positive changes in the cognitive flexibility of adults are significantly associated with improving social performance and their psychological health (Scott et al., 2017).

Cognitive flexibility encompasses a broad spectrum of human mental abilities to accommodate different situational needs. In many types of mental disorders, these inflexible mental and behavioral processes are inefficient (Kashdan \& Rottenberg, 2010). Since cognitive flexibility from clinical psychology approach is related to health and welfare, it is necessary to improve the cognitive flexibility of the patients with thalassemia as the main domain in clinical psychology Whiting, Deane, Simpson, McLeod, and Ciarrochi (2017). To date, numerous studies have conducted to evaluate the efficacy of ACT on different diseases, for example Whiting et al (2017) aimed to evaluate effect of ACT method in psychological adjustment of patients with brain injury and the results of their studies suggested the efficacy of ACT method to alleviate psychological problems followed by physiological diseases.

Besides, there are more examples of the studies on ACT use as an effective method to deal with psychological complications of a variety of diseases for instance anxiety in patients with stroke (Sianturi, Keliat, \& Wardani, 2018) or other chronic physical illnesses (Brassington et al., 2016). However, to the best of our knowledge, no research has ever tried to evaluate the efficacy of ACT method to improve psychological problems in patients with thalassemia. Therefore, we designed this study to fill this gap. The main advantage of the ACT method in comparison with other psychotherapy methods is its focus on motivational and cognitive aspects to have a more profound influence and enhance the durability of the treatment's effectiveness (Har- ley, 2015). Because there is no research on the effectiveness of ACT method on psychological flexibility problems of thalassemia, the present research aimed to answer the question of whether ACT training can improve the mental flexibility of students with thalassemia or not.

\section{Methods}

This research is a quasi-experimental study with pre-test, post-test, and follow-up conducted on two groups (experimental and waiting group). In this research, the statistical population consisted of all senior elementary and junior high school students with thalassemia major living in Zahedan city, Iran, who had a medical profile in Thalassemia Department of Ali Asghar Hospital in Zahedan. To determine the research sample size, the Cohen table (1986) was used. Thirty samples were selected for each group (experimental and waiting) by considering the error rate of $0.05(\alpha=0.05)$, an effect size of 0.50 , and the test power of 0.97 .

The sampling was performed by the purposive sampling method. The samples were randomly divided into experimental $(n=30)$ and the waiting group $(n=30)$. Because one subject from the third session and one subject from the fourth session did not participate in the treatment sessions of the experimental group and it was not possible to access two subjects of the waiting group, the research sample size was reduced to 28 patients in the experimental group and 28 subjects in the waiting group. Also, Figure 1 shows the study flow diagram that is in concordance with the CONSORT flow diagram. The obtained data were analyzed according to these numbers.

The inclusion criteria were as follows: having thalassemia based on the medical records and tests recorded in the patients' medical profile, living in Zahedan, studying at the senior elementary or junior high school (This age range covered the largest thalassemia patients of Ali Asghar Hospital), and collaborating with the planned programs. The exclusion criteria were as follows: lacking other diseases according to the physician's opinion and not participating in other psychological interventions.

The Cognitive Flexibility Inventory (CFI), developed by Dennis and Vander Wal (2010) was used to evaluate the psychological flexibility of the subjects. This questionnaire is a brief self-report questionnaire consisting of 20 questions. It measures a type of cognitive flexibility needed for the individuals that have challenges with problematic thoughts and situations, and are unable to replace inefficient thoughts with more efficient ones. It is scored based on a 7-point Likert-type scale and measures three aspects of cognitive flexibility: the desire to 
understand problematic situations as controllable states (perceived control), ability to understand several alternative explanations for life incidences and human behavior (perception of behavior justification), and the ability to create multiple alternative solutions for challenging situations (perception of different options).

According to Dennis and Vander Wal (2010), this questionnaire has a reliable two-factor structure, desirable internal consistency, and a high 7-week test-retest reliability. The concurrent validity of this questionnaire with Beck Depression Inventory (BDI-II) was -0.39 , and its convergent construct validity with the cognitive flexibility scale of Martin and Rubin (1995) was 0.75. The researchers evaluated the validity of the questionnaire by Cronbach's $\alpha$ for the whole scale, the perceived control of the choice, and the perception of different options that were $0.91,0.84$, and 0.91, respectively. Moreover, the test-retest reliability values of the mentioned scales were $0.81,0.77,0.75$, respectively (Dennis \& Vander Wal, 2010). Kohandani and Abu al-Ma'ali al-Husseini (2017) studied the psychometric properties of the Persian version of the Denis, Vander cognitive flexibility questionnaire on 490 Iranian people. The results showed that the internal consistency of the total score of this questionnaire, the problem-solving process, and the perceived controllability were $0.893,0.779,0.81$, respectively.

After obtaining the necessary permissions from the Education and Health Deputy of the University of Zahedan Medical Sciences, the Ethics Committee assigned an approval code (code: 4900.76953.6.53) and referred us to the Thalassemia Department of Ali Asghar Hospital in Zahedan. The goals, method, and importance of the research were fully explained to the patients. Also, the students' anonymity and confidentiality were assured. Then, the patients provided written informed consent to participate in the research in the presence of their parents. The community officials are also assured that they would receive the research results.

Generally, ACT interventions are implemented once a week in one or two sessions (Morris, Johns, \& Oliver, 2013). In the present study, we decided to hold treatment sessions twice a week, due to the parents' desire to finish the sessions sooner and the likelihood of dropping subjects due to incoming vacations. After the pre-test, the therapeutic intervention was conducted in two 120-minute sessions per week (for one month) for the experimental group, and the waiting group did not receive the intervention. Due to the ethical considerations, protective counseling sessions were held for the waiting group. It is worth mentioning that these protective counseling methods did follow special protocol to decrease the risk of any possible bias. In the counseling sessions, we focused on individuals that have daily problems related to their diseases and gave them some advice pertaining to their specific issues.

Considering the ethical issues, the psychotherapy sessions were carried out after the end of the research and the disclosure of the results. In this study, we followed the ethical guidelines of the Declaration of Helsinki 1975. After the end of the therapy sessions, the post-test was performed on both groups, and two months later, the follow-up test was performed. The treatment method used in this study was an extended version of the treatment plan for ACT (Hayes, Levin, Plumb-Vilardaga, Villatte, \& Pistorello, 2013). The intervention sessions are summarized in Table 1 (Clarke et al., 2014). Data analysis was performed in SPSS version 16, and descriptive statistics and repeated Measures Analysis of Variance (ANOVA) were used to assess the obtained information.

\section{Results}

Table 2 presents the demographic information of the research samples. The Mean \pm SD age of the experimental group was $12.61 \pm 1.91$ years and Mean $\pm \mathrm{SD}$ age of the waiting group was $12.32 \pm 1.72$ years. Table 3 presents the mean and standard deviation of psychological flexibility scores of the waiting and intervention groups in three stages of performed assessments. As Table 3 shows, the mean score of psychological flexibility in the experimental group increased from 77.68 in the pre-test to 89.46 in the post-test. This increase in the score was maintained at the follow-up stage, whereas the mean score of cognitive flexibility has no significant difference in the waiting group in the three stages of the experiment

Before performing the repeated measures ANOVA, the differences between the experimental and waiting groups in terms of demographic variables and pre-test scores were calculated (Table 2). Furthermore, ANOVA assumptions by the Box test were examined. The results of the Box test showed that the observed covariance matrix of the dependent variable was the same among the different groups $(\mathrm{F}=1.415, \mathrm{P}=0.204)$. One of the other assumptions was the equality of variance of the scores of the groups in three stages of pre-test, post-test, and two-month follow-up, which was tested by the Levene's test.

The results of the test in the pre-test $\left(\mathrm{F}_{1.54}=0.262\right.$, $\mathrm{P}=0.611)$, post-test $\left(\mathrm{F}_{1.54}=0.042, \mathrm{P}=0.839\right)$, and follow up $\left(\mathrm{F}_{1.54}=0.003, \mathrm{P}=0.109\right)$ indicate that the variances of groups are not significantly different, in other words, the assumption met the criteria. In the next step, the other assumption, Mauchly's Sphericity Test, was examined. Because sphe- 
Table 1. Summary of the structure and content of treatment sessions based on the ACT protocol

\begin{tabular}{|c|c|c|}
\hline Sessions & Topic & Content \\
\hline Pre-session & $\begin{array}{l}\text { Creating initial communica- } \\
\text { tions }\end{array}$ & $\begin{array}{l}\text { Proper communication to build trust, how to complete the questionnaire cor- } \\
\text { rectly, and to perform the pre-test }\end{array}$ \\
\hline First & $\begin{array}{l}\text { Introducing the ACT treat- } \\
\text { ment method }\end{array}$ & $\begin{array}{l}\text { Introducing the ACT method, its main goals, and outlines, determining the } \\
\text { rules that individuals must follow in each session, reviewing the relevant } \\
\text { treatments, costs, and benefits }\end{array}$ \\
\hline Second & $\begin{array}{l}\text { Evaluation of personal } \\
\text { feedback, expectations, and } \\
\text { tendency to change }\end{array}$ & $\begin{array}{c}\text { A review of the past session experiences and receiving feedbacks, discussing } \\
\text { their experiences. Evaluate the person's willingness to change expectations } \\
\text { for the ACT, creation of creative helplessness, summing up the discussion and } \\
\text { giving homework }\end{array}$ \\
\hline Third & $\begin{array}{l}\text { Clarification of ACT strate- } \\
\text { gies and inefficient control } \\
\text { and resistance }\end{array}$ & $\begin{array}{l}\text { A review of the past session experiences and feedbacks, identifying ineffec- } \\
\text { tive control strategies and understanding their futility, explaining the concept } \\
\text { of acceptance and its difference with the failure, despair, denial, and resis- } \\
\text { tance and finally discussing the challenges along with accepting the disease }\end{array}$ \\
\hline Fourth & Behavioral commitment & $\begin{array}{l}\text { A review of the past session experiences and feedback. Explanation of behav- } \\
\text { ioral commitment. Introducing and understanding self-conceptualization, cog- } \\
\text { nitive defusion, and application of cognitive defusion techniques, intervention } \\
\text { in problematic chain of language and metaphors, summing up the session } \\
\text { and reviewing the practical exercises of the next session and providing a } \\
\text { homework assignment }\end{array}$ \\
\hline Fifth & Self-awareness training & $\begin{array}{c}\text { A review of the past session. The explanation of the concept of separation of } \\
\text { oneself, inner experiences and behavior, seeing themselves as a context, self- } \\
\text { conceptual weakening, and self-expression. In this section, the participants } \\
\text { learn to focus on their activities (such as breathing, walking, etc.) and be } \\
\text { aware of their condition at any moment }\end{array}$ \\
\hline Sixth & $\begin{array}{l}\text { Identification and reaffirm- } \\
\text { ing the values of partici- } \\
\text { pants' life }\end{array}$ & $\begin{array}{l}\text { A review of the past session, identification of patients' life values and reaf- } \\
\text { firming, and focusing on them, attention to the power of selecting them. } \\
\text { Using mindfulness techniques with an emphasis on the present time }\end{array}$ \\
\hline Seventh & $\begin{array}{l}\text { Clarification of values, goals } \\
\text { and common mistakes in } \\
\text { choosing values }\end{array}$ & $\begin{array}{l}\text { A review of the past session. Talking and discussing the values of the partici- } \\
\text { pants and reflecting on the previous concepts. Elucidating the differences } \\
\text { between values, goals, and common mistakes in choosing values. Also, pos- } \\
\text { sible internal and external barriers to pursuing values are discussed. Members } \\
\text { list their most important values and possible obstacles in tracking them and } \\
\text { shared with other members. Objectives related to the values and character- } \\
\text { istics of the goals (specific, measurable, realistic, and in line with personal } \\
\text { values) are discussed in the group. Then the members set out three of their } \\
\text { most important values and determine the goals they want to pursue for } \\
\text { each of those values, and finally, they define the actions/ behaviors that they } \\
\text { intend to accomplish to fulfill those goals. Showing the dangers of focusing on } \\
\text { the results }\end{array}$ \\
\hline Eighth & $\begin{array}{l}\text { Learning to be committed } \\
\text { to action }\end{array}$ & $\begin{array}{c}\text { Understanding the nature of committed action. Identification of behavioral } \\
\text { patterns in accordance with the values and commit to act on them. Emphasis } \\
\text { on some points about the concept of relapse and readiness to deal with } \\
\text { them. Review assignments and summing up meetings with individuals. Shar- } \\
\text { ing the experiences of group members with achievements and expectations } \\
\text { that were not met, and finally, the patients are thanked for participating in } \\
\text { the group, and the post-test is administered }\end{array}$ \\
\hline
\end{tabular}

PRACTICE In
CLINICAL PSYCH LOGY

ricity violation was found, the Greenhouse-Geisser correction was used to investigate the intra-group effect for the psychological flexibility variable (Table 4). The results of repeated measures ANOVA showed that the time factor in the dependent variable (cognitive flexibility) is significant. In other words, increasing the cognitive flexibility of the participants during the post-test and follow-up $(\mathrm{F}=63.823$, $\mathrm{P}=0.001$ ) with the effect size of 0.542 , as well as the time and group interaction for this variable $(\mathrm{F}=62.490, \mathrm{P}=0.001)$ with the effect size of 0.536 were significant.
Besides, the difference between the experimental and waiting groups is significant regarding the psychological flexibility scores with an effect size of 0.094 . To examine whether the difference between the observed psychological flexibility changes is significant, the Bonferroni post hoc test was used. Table 5 reports the results. According to Table 5, the difference between the means of the post-test and the pre-test scores of psychological flexibility is significant. Meanwhile, the difference between the means of follow-up and pre-test of psychological flexibility scores is also significant, but the difference between means of follow-up and 
Table 2. The differences between experimental and waiting groups in terms of demographic variable and pre-test $(n=28)$

\begin{tabular}{|c|c|c|c|c|}
\hline \multirow{2}{*}{\multicolumn{2}{|c|}{ Variable }} & \multicolumn{2}{|c|}{ No. (\%) } & \multirow{2}{*}{$P$} \\
\hline & & Experimental & Waiting & \\
\hline \multirow{3}{*}{ Age, $y$} & $10-13$ & $20(71.4)$ & $21(75)$ & \multirow{3}{*}{0.55} \\
\hline & $14-17$ & $8(28.6)$ & $7(35)$ & \\
\hline & Mean \pm SD & $12.61 \pm 1.92$ & $12.32 \pm 1.72$ & \\
\hline \multirow[b]{2}{*}{ Sex } & Boy & $16(57.1)$ & $17(60.7)$ & \multirow[b]{2}{*}{0.76} \\
\hline & Girl & $12(42.9)$ & 11(39.3) & \\
\hline \multirow[b]{2}{*}{ Grade } & Senior Elementary & $17(60.7)$ & $18(64.3)$ & \multirow[b]{2}{*}{0.76} \\
\hline & Junior high school & $11(39.3)$ & 10(35.7) & \\
\hline Pre-test score & Mean $\pm S D$ & $77.68 \pm 14.93$ & $76.50 \pm 14.04$ & 0.76 \\
\hline
\end{tabular}

post-test scores of psychological flexibility is not significant. These results show the sustainability of the effect of ACT therapy on the variable of psychological flexibility in the experimental group in the follow-up phase.

\section{Discussion}

The results of this study indicate that ACT training in creases the cognitive flexibility of patients with thalassemia. This finding is consistent with the results of the previous studies (McCracken \& Gutiérrez-Martínez, 2011; McCracken \& Morley, 2014; Scott et al., 2017). In McCracken and Gutiérrez-Martínez (2011) study, ACT was performed on 168 patients suffered from chronic pain. Their results show that this treatment method significantly increases the psychological flexibility of the patients (McCracken \& Gutiérrez-Martínez, 2011).
Our study results are understandable when we realize that ACT potentially focuses on the behavior and the context in which the behavior occurs. The purpose of the ACT is to place the person's behaviors in a position that is effective in terms of the individuals' defined values and desires (Bach \& Moran, 2008). Therefore, psychological flexibility can be considered as a well-known outcome of ACT (Diane \& Whiting, 2017). Mazzone, Battaglia, Andreozzi, Romeo, and Mazzone (2009) in their study tried to screen the effectiveness of Cognitive-Behavioral Family Therapy (CBFT) on emotional impact in children with $\beta$-thalassemia major. According to their findings, CBFT is a valid tool to decrease the psychological complication in children with $\beta$-thalassemia. However, they develop important psychological problems after CFBT intervention.

Our comprehensive search shows that most psychological studies that conducted on patients with thalassemia have tried to assess different aspects of their mental properties

Table 3. The mean and standard deviation of the psychological flexibility score in the study groups separated by stages

\begin{tabular}{lccc}
\hline \multicolumn{1}{c}{ Group } & Number & Mean \pm SD \\
\hline \multirow{2}{*}{ Experimental } & Pre-test & 28 & $77.68 \pm 2.73$ \\
& Post-test & 28 & $89.46 \pm 2.75$ \\
& Two-month follow-up & 28 & $89.07 \pm 2.58$ \\
Waiting & Pre-test & 28 & $76.50 \pm 2.73$ \\
& Post-test & 28 & $77.03 \pm 2.75$ \\
& Two-month follow-up & 28 & $76.03 \pm 2.58$ \\
\hline
\end{tabular}


Table 4. The results of repeated measures ANOVA of intergroup and intragroup effects of psychological flexibility

\begin{tabular}{|c|c|c|c|c|c|c|c|}
\hline \multicolumn{2}{|r|}{ Effect } & $\begin{array}{l}\text { Sum of } \\
\text { Squares }\end{array}$ & $\begin{array}{l}\text { Degrees of } \\
\text { Freedom }\end{array}$ & $\begin{array}{l}\text { Mean of } \\
\text { Squares }\end{array}$ & $F$ & $\mathbf{P}$ & $\begin{array}{c}\text { ETA } \\
\text { Squares }\end{array}$ \\
\hline Intergroup & Group & 3312.595 & 1 & 3312.595 & 5.621 & 0.021 & 0.094 \\
\hline \multirow{2}{*}{ Intragroup } & $\begin{array}{l}\text { Measurement time } \\
\text { (pre-test, post-test, } \\
\text { follow-up) }\end{array}$ & 1274.89 & 1.408 & 905.629 & 63.823 & 0.000 & 0.562 \\
\hline & $\begin{array}{l}\text { Time and group } \\
\text { interaction }\end{array}$ & 1248.440 & 1.408 & 886.838 & 62.490 & 0.000 & 0.536 \\
\hline
\end{tabular}

Table 5. Bonferroni post-test results of the psychological flexibility variable

\begin{tabular}{|c|c|c|c|c|c|c|}
\hline $\begin{array}{c}\text { Dependent } \\
\text { Variable }\end{array}$ & \multicolumn{2}{|c|}{ Pre-test/ Post-test } & \multicolumn{2}{|c|}{ Pre-test/ Follow up } & \multicolumn{2}{|c|}{ Post-test/ Follow up } \\
\hline Psychological & $\begin{array}{l}\text { Difference in } \\
\text { means }\end{array}$ & SE & $\begin{array}{l}\text { Difference } \\
\text { in means }\end{array}$ & SE & $\begin{array}{l}\text { Difference in } \\
\text { means }\end{array}$ & SE \\
\hline & $-6.62 *$ & 0.653 & -5.464 & 0.725 & 0.696 & 0.0 .344 \\
\hline
\end{tabular}

SE: Standard Error; $* \mathrm{P}<0.001$

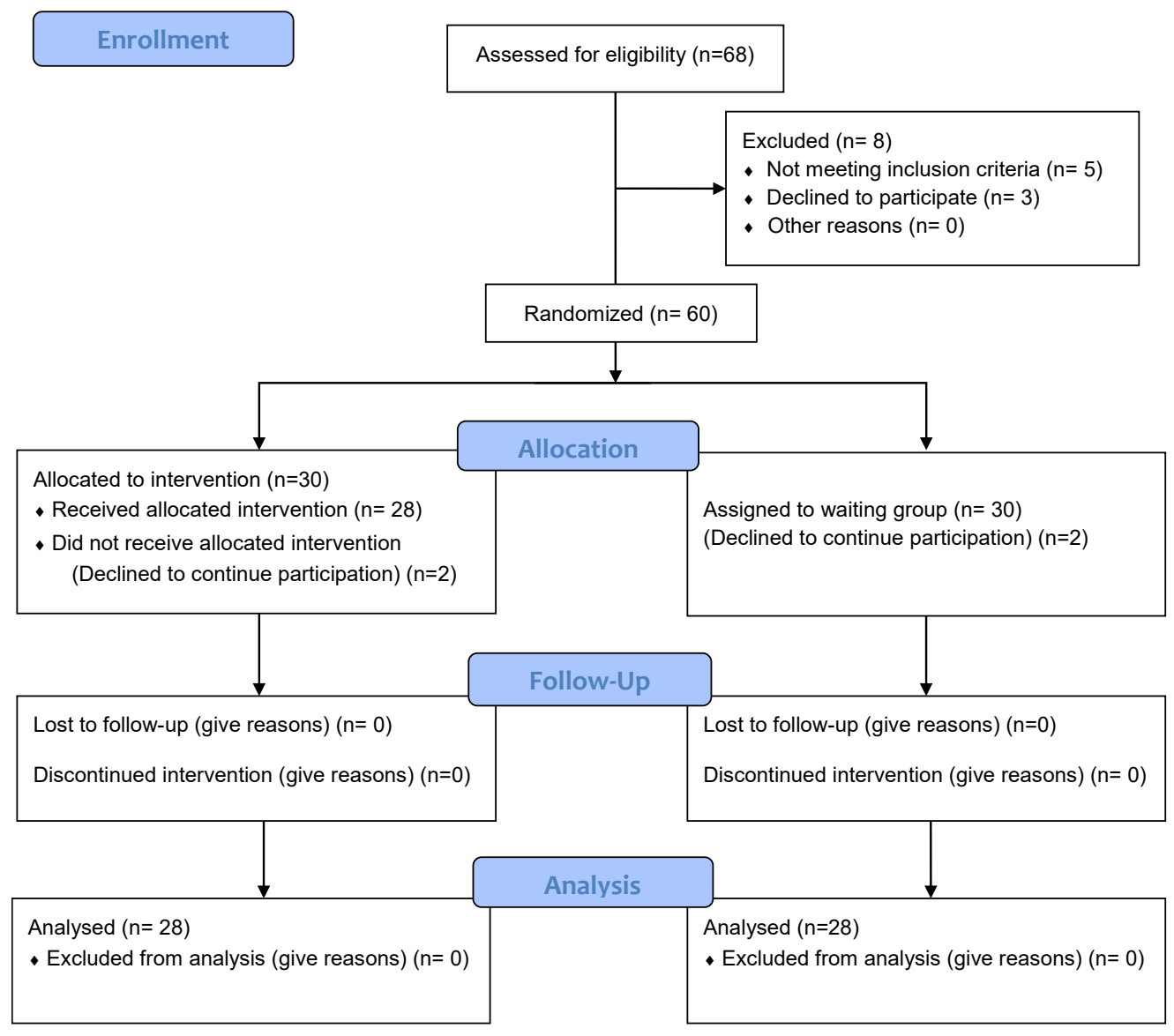

Figure 1. The study flow diagram 
(Behdani et al., 2015; Pattanashetti, Mugali, Pattanashetty, \& Patil, 2017) but there are no psychological interventional studies on their problems with the ACT method. In the process of treatment by the ACT, psychological flexibility has introduced as the basis of psychological health. Also, following the theory of cognitive flexibility, mental health is defined as the acceptance of the internal and external situations of the individual and the commitment to activities that are valuable in a sustainable way. Different forms of psychopathological vulnerabilities are also described based on the cognitive flexibility theory through "excess in maladaptive behavioral or emotional rules", or by "value-centered behaviors and hypersensitivity to probabilities related to the future" (Dionne, Ngô, \& Blais, 2013).

Given the 6 processes of ACT; connection, defusion, expansion, observing self, values, committed action and the 6 processes of psychological inflexibility; dominance of the conceptualized past or future-limited self-knowledge, cognitive fusion, experiential avoidance, attachment to the conceptualized self, lack of values clarity/contact and unworkable action, the current study was conducted to obviate the mentioned problems by related ACT strategies.

In the process of ACT, people are encouraged to accept responsibility for behavioral changes. This treatment seeks to balance behaviors according to the situations. In areas that change is possible (e.g. behavior), ACT focuses on strategies that lead to transformation, and conversely, where change is impossible (such as blood pressure, thalassemia, diabetes), it focuses on acceptance and practices mindfulness.

Mindfulness helps people adopt and have less avoidance behavior (Bach \& Moran, 2008). Thus, patients learn during the treatment sessions to distinguish between themselves as a human being and their psychological content involved with them (self as a background). They learn to experience the content without excuses, as they are, and not as they want to be (acceptance). They encouraged to be themselves not what they desire to be (defusion), connect with the present moment, choose their values, and do what that leads to reaching to the goals (commitment). Following the mentioned approach will result in psychological flexibility (Flaxman, Blackledge, \& Bond, 2010).

In this study, we highlighted that patients with thalassemia need help to deal flexibly with what life offers them. Therefore, behavioral changes and acceptance become stronger and stable at the present moment. ACT tries to guide the person to manage mental content based on the reality of what is happening right now and shapes logical interactions with what goes around, through communication with the moment, and this process enhances the persons' psychological flexibility (Hayes \& Strosahl, 2004).

Moreover, the results of this study show the durability of the ACT method in increasing the psychological flexibility of the patients with thalassemia in the follow-up phase. This finding agrees with the studies that have reported the efficacy of ACT in improving psychological problems of different disorders even after one or two years (Brassington et al., 2016; Lappalainen et al., 2014; McCracken \& Gutiérrez-Martínez, 2011; Sianturi et al., 2018). It can be said that patients learn to take an active stand in the world and make their lives based on ACT strategies (Flaxman et al., 2010).

In general, according to the results of this study and previous studies, new psychological approaches such as ACT about its effectiveness and its applications can be used to increase psychological flexibility and treat disorders comorbid with psychological complications. As a result, the patients will be able to psychologically and effectively manage their problems and encounter their problems more efficiently (Bond, Hayes, \& Barnes-Holmes, 2006). This study has some limitations such as the nonrandom selection of samples (although in the next step, the samples randomly assigned to experimental and waiting groups), low sample size, use of self-reporting scales (so the possibility of bias in responses), and the non-generalizability of the results to other clinical populations.

However, we suggest using the current therapeutic approach in psychological and educational disorders and also to improve the psychological health and quality of life of different patient groups. The policymakers are recommended to implicate our study results in their plans about patients with chronic diseases. We also suggest that future studies evaluate the effectiveness of this method on psychological flexibility in other age ranges, racial groups, with a bigger sample size for generalization of the results. Moreover, using different screening tools for measuring psychological flexibility before and after ACT intervention could validate the findings.

In sum, considering the obtained results, ACT is an applicable psychotherapy method that helps the patients with thalassemia increase their psychological flexibility and cope with special psychological problems of their disease. To our knowledge, this is the first report of ACT effectiveness to prevent thalassemia patients' psychological problems. This aspect of the research suggested that ACT is an applicable and effective method to increase the psychological flexibility in students with thalassemia. The possibility of the ACT effectiveness for improving other psychological 
problems of other diseases warrants further investigations and optimization of this method for practical implications of different illnesses.

\section{Ethical Considerations}

\section{Compliance with ethical guidelines}

This study was approved by the Research Ethics Committee of Zahedan University of Medical Science (code: 4900.76953.6.53) and conducted at the Thalassemia Department of Ali Asghar Hospital in Zahedan, Iran. The goals, method, and importance of the research were fully explained to the patients. Also, the students' anonymity and confidentiality were assured. Then, the patients provided written informed consent to participate in the research in the presence of their parents. The community officials are also assured that they would receive the research results.

\section{Funding}

This research did not receive any specific grant from funding agencies in the public, commercial, or not-forprofit sectors

\section{Authors' contributions}

Methodology, investigation, writing: Homeira Mahmoudi Souran; Conceptualization, writing, review and editing: Mahmoud Shirazi; Supervision, conceptualization: Gholam Reza Sanagouyemoharer

\section{Conflict of interest}

The authors declared no conflict of interest.

\section{Acknowledgments}

Our sincere thanks also go to advisors of Rahgoshaye Elm va Pajohesh Institute for their helpful comments to conduct this work.

\section{References}

Abolghasemi, H., Amid, A., Zeinali, S., Radfar, M. H., Eshghi, P., Rahiminejad, M. S., et al. (2007). Thalassemia in Iran: Epidemiology, prevention, and management. Journal of Pediatric Hematology/Oncology, 29(4), 233-8. [DOI:10.1097/MPH.0b013e3180437e02] [PMID]
Bach, P. A., \& Moran, D. J. (2008). ACT in practice: Case conceptualization in acceptance and commitment therapy. Oakland: New Harbinger Publications.

Behdani, F., Badiee, Z., Hebrani, P., Moharreri, F., Badiee, A. H., Hajivosugh, N., et al. (2015). Psychological aspects in children and adolescents with major thalassemia: A case-control study. Iranian Journal of Pediatrics, 25(3), e322. [DOI:10.5812/ ijp.25(3)2015.322] [PMID] [PMCID]

Bond, F. W., Hayes, S. C., \& Barnes-Holmes, D. (2006). Psychological flexibility, ACT, and organizational behavior. Journal of Organizational Behavior Management, 26(1-2), 25-54. [DOI:10.1300/ J075v26n01_02]

Brassington, L., Ferreira, N. B., Yates, S., Fearn, J., Lanza, P., Kemp, K., et al. (2016). Better living with illness: A transdiagnostic acceptance and commitment therapy group intervention for chronic physical illness. Journal of Contextual Behavioral Science, 5(4), 208-14. [DOI:10.1016/j.jcbs.2016.09.001]

Clarke, S., Kingston, J., James, K., Bolderston, H., \& Remington, B. (2014). Acceptance and commitment therapy group for treatment-resistant participants: A randomized controlled trial. Journal of Contextual Behavioral Science, 3(3), 179-88. [DOI:10.1016/j. jcbs.2014.04.005]

Dennis, J. P., \& Vander Wal, J. S. (2010). The cognitive flexibility inventory: Instrument development and estimates of reliability and validity. Cognitive Therapy and Research, 34(3), 241-53. [DOI:10.1007/s10608-009-9276-4]

Dionne, F., Ngô, T. L., \& Blais, M. C. (2013). The psychological flexibility model: A new approach to mental health. Sante Mentale au Quebec, 38(2), 111-30. [DOI:10.7202/1023992ar] [PMID]

Flaxman, P. E., Blackledge, J. T., \& Bond, F. W. (2010). Acceptance and commitment therapy: Distinctive features. Abingdon: Routledge. [DOI:10.4324/9780203834688]

Gandy, M., Karin, E., Jones, M. P., McDonald, S., Sharpe, L., Titov, N., \& Dear, B. F. (2018). Exploring psychological mechanisms of clinical response to an internet-delivered psychological pain management program. European Journal of Pain, 22(8), 1502-16. [DOI:10.1002/ejp.1239] [PMID]

Harley, J. (2015). Bridging the gap between cognitive therapy and Acceptance and Commitment Therapy (ACT). ProcediaSocial and Behavioral Sciences, 193, 131-40. [DOI:10.1016/j.sbspro.2015.03.252]

Hayes, S. C., Levin, M. E., Plumb-Vilardaga, J., Villatte, J. L., \& Pistorello, J. (2013). Acceptance and commitment therapy and contextual behavioral science: Examining the progress of a distinctive model of behavioral and cognitive therapy. Behavior Therapy 44(2), 180-98. [DOI:10.1016/j.beth.2009.08.002] [PMID] [PMCID]

Hayes, S. C., Pistorello, J., \& Levin, M. E. (2012). Acceptance and commitment therapy as a unified model of behavior change. The Counseling Psychologist, 40(7), 976-1002. [DOI:10.1177/0011000012460836]

Hayes, S. C., \& Strosahl, K. D. (2004). A practical guide to acceptance and commitment therapy. Berlin: Springer Science \& Business Media. [DOI:10.1007/978-0-387-23369-7]

Kashdan, T. B., \& Rottenberg, J. (2010). Psychological flexibility as a fundamental aspect of health. Clinical Psychology Review, 30(7), 865-78. [DOI:10.1016/j.cpr.2010.03.001] [PMID] [PMCID] 
Kelso, K. C. (2017). Inside this moment: a clinician's guide to promoting radical change using acceptance and commitment therapy. Cognitive Behaviour Therapy, 46(2), 174

Strosahl, K. D., Robinson, P. J., \& Gustavsson, T. (2015). Inside this moment: A clinician's guide to promoting radical change using acceptance and commitment therapy. Oakland, California: New Harbinger Publications. [DOI:10.1080/16506073.2016.1198418]

Kohandani, M., \& Abolmaali Alhosseini, K. (2017). [Factor structure and psychometric properties of Persian version of cognitive flexibility of Dennis, Vander Wal and Jillon (Persian)]. Journal of Psychological Methods and Models, 8(29), 53-70.

Lappalainen, P., Granlund, A., Siltanen, S., Ahonen, S., Vitikainen, M., Tolvanen, A., et al. (2014). ACT internet-based vs face-toface? A randomized controlled trial of two ways to deliver acceptance and commitment therapy for depressive symptoms: An 18-month follow-up. Behaviour Research and Therapy, 61, 43-54. [DOI:10.1016/j.brat.2014.07.006] [PMID]

Martin, M. M., \& Rubin, R. B. (1995). A new measure of cognitive flexibility. Psychological Reports, 76(2), 623-6. [DOI:10.2466/ pr0.1995.76.2.623]

Masuda, A., \& Tully, E. C. (2012). The role of mindfulness and psychological flexibility in somatization, depression, anxiety, and general psychological distress in a nonclinical college sample. Journal of Evidence-Based Complementary $\mathcal{E}$ Alternative Medicine, 17(1), 66-71. [DOI:10.1177/2156587211423400]

Mazzone, L., Battaglia, L., Andreozzi, F., Romeo, M. A., \& Mazzone, D. (2009). Emotional impact in $\beta$-thalassaemia major children following cognitive-behavioural family therapy and quality of life of caregiving mothers. Clinical Practice and Epidemiology in Mental Health, 5, 5. [DOI:10.1186/1745-0179-5-5] [PMID] [PMCID]

McCracken, L. M., \& Gutiérrez-Martínez, O. (2011). Processes of change in psychological flexibility in an interdisciplinary groupbased treatment for chronic pain based on Acceptance and Commitment Therapy. Behaviour Research and Therapy, 49(4), 267-74. [DOI:10.1016/j.brat.2011.02.004] [PMID]

McCracken, L. M., \& Jones, R. (2012). Treatment for chronic pain for adults in the seventh and eighth decades of life: A preliminary study of Acceptance and Commitment Therapy (ACT). Pain Medicine, 13(7), 861-7. [DOI:10.1111/j.1526-4637.2012.01407.x] [PMID]

McCracken, L. M., \& Morley, S. (2014). The psychological flexibility model: A basis for integration and progress in psychological approaches to chronic pain management. The Journal of Pain, 15(3), 221-34. [DOI:10.1016/j.jpain.2013.10.014] [PMID]

Morris, E. M., Johns, L. C., \& Oliver, J. E. (2013). Acceptance and commitment therapy and mindfulness for psychosis. Hoboken: John Wiley \& Sons. [DOI:10.1002/9781118499184]

Padhi, S., Maharshi, S., Gupta, G. K., Garg, K., \& Nijhawan, S. (2018). Efficacy and safety of direct acting antiviral therapy for chronic hepatitis C in Thalassemic children. Journal of Pediatric Hematology/Oncology, 40(7), 511-4. [DOI:10.1097/MPH.0000000000001217] [PMID]

Pattanashetti, M., Mugali, J., Pattanashetty, N., \& Patil, S. (2017). A study of severity of depression in Thalassemia patients. The International Journal of Indian Psychology, 4(2), 33.

Scott, W., Daly, A., Yu, L., \& McCracken, L. M. (2017). Treatment of chronic pain for adults 65 and over: Analyses of outcomes and changes in psychological flexibility following interdisciplinary Acceptance and Commitment Therapy (ACT). Pain Medicine, 18(2), 252-264. [DOI:10.1093/pm/pnw073] [PMID]

Shafiee, A., Nazari, S., Jorjani, S., Bahraminia, E., \& SadeghiKoupaei, M. (2014). Prevalence of depression in patients with $\beta$-thalassemia as assessed by the beck's depression inventory. Hemoglobin, 38(4), 289-91. [DOI:10.3109/03630269.2014.929008] [PMID]

Sianturi, R., Keliat, B. A., \& Wardani, I. Y. (2018). The effectiveness of acceptance and commitment therapy on anxiety in clients with stroke. Enfermeria Clinica, 28, 94-7. [DOI:10.1016/S11308621(18)30045-7]

Whiting, D. L. (2016). A trial of acceptance and commitment therapy to facilitate psychological adjustment after a traumatic brain injury [PhD. dissertation]. Wollongong: University of Wollongong.

Whiting, D. L., Deane, F. P., Simpson, G. K., McLeod, H. J., \& Ciarrochi, J. (2017). Cognitive and psychological flexibility after a traumatic brain injury and the implications for treatment in acceptance-based therapies: A conceptual review. Neuropsychological Rehabilitation, 27(2), 263-99. [DOI:10.1080/09602011.2015.1 062115] [PMID]

Yaghobi, M., Miri-Moghaddam, E., Majid, N., Bazi, A., Navidian, A., \& Kalkali, A. (2017). Complications of transfusion-dependent $\beta$-thalassemia patients in Sistan and Baluchistan, south-east of Iran. International Journal of Hematology-Oncology and Stem Cell Research, 11(4), 268-72. [PMID] [PMCID]

Yengil, E., Acipayam, C., Kokacya, M. H., Kurhan, F., Oktay, G., \& Ozer, C. (2014). Anxiety, depression and quality of life in patients with beta thalassemia major and their caregivers. International Journal of Clinical and Experimental Medicine, 7(8), 2165-72. [PMID] [PMCID] 